Article

\title{
A Comparative Study of MFI Zeolite Derived from Different Silica Sources: Synthesis, Characterization and Catalytic Performance
}

\author{
Jianguang Zhang ${ }^{1}$, Xiangping $\mathrm{Li}^{2}{ }^{2}{ }$, Juping Liu ${ }^{2}$ and Chuanbin Wang ${ }^{2}$ \\ 1 School of Petroleum engineering, China University of Petroleum (East China), Qingdao 266580, China; \\ eduzjg@163.com \\ 2 School of Environmental Science and Engineering/China-Australia Centre for Sustainable Urban \\ Development, Tianjin University, Tianjin 300072, China; liujuping1234@163.com (J.L.); \\ wangchuanbin6@163.com (C.W.) \\ * Correspondence: xiangping.li@tju.edu.cn; Tel.: +86-022-8740-1929
}

Received: 13 November 2018; Accepted: 25 December 2018; Published: 26 December 2018

check for updates

\begin{abstract}
In this paper, a comparative study of MFI zeolite derived from different silica sources is presented. Dry gel conversion (DGC) method is used to synthesize silicalite-1 and ZSM- 5 with MFI structure. Two kinds of silica sources with different particle sizes are used during the synthesis of MFI zeolite. The as-prepared samples were characterized by X-ray diffraction (XRD), $\mathrm{N}_{2}$-sorption, Fourier transform infrared spectroscopy (FTIR), Scanning electron microscopy (SEM) and X-ray fluorescence spectrometer (XRF). From the characterization results, it could be seen that the high-quality coffin-like silicalite-1 was synthesized using silica sphere with particle size of $300 \mathrm{~nm}$ as silica source, with crystallization time being shortened to $2 \mathrm{~h}$. The schematic diagram of silicalite- 1 formation using silica sources with different particle sizes is summarized. ZSM- 5 was obtained by adding $\mathrm{Al}$ atoms to raw materials during the synthesis of MFI zeolite. The performance of aqueous phase eugenol hydrodeoxygenation over Pd/C-ZSM-5 catalyst is evaluated.
\end{abstract}

Keywords: dry gel conversion; MFI zeolite; particle sizes; silica sources; hydrodeoxygenation

\section{Introduction}

The structure of crystalline aluminosilicates is three dimensional and always contains cages or pores, making them very favorable. Meanwhile, due to their extremely high thermal stability and chemical resistance, they have been widely used in industrial production [1-6]. Owing to tunable porosity and molecule shape selectivity, zeolites can be used as adsorbent, ion-exchange material and catalysts, and so on [7-11]. A large variety of reactions such as cracking, isomerization, dewaxing, dehydration, hydrodeoxygenation and alkylation can be accomplished with microporous zeolites [12-18]. Moreover, the applications of zeolites in the fields of separation, chemical sensors, anticorrosive coating, low-k materials, and hydrophilic antimicrobial coatings are a research hotspot at present [19-22]. As a well-known microporous aluminosilicate [23,24] firstly synthesized by scientists in 1969, ZSM-5 zeolite has a 3D host framework of intersecting 10-membered rings, with a pore size of $(0.51 \times 0.55 \mathrm{~nm})$ in the [100] direction.

Various methods can be used to synthesize MFI zeolite, including the hydrothermal synthesis method [25-27], the microwave irradiation method [28], and so on. Conventional methods for synthesis of MFI zeolite are often associated with long synthesis times and large quantities of template agents, which leads to increasing cost. In addition, MFI zeolite with low degrees of crystallinity is obtained from synthesis processes using conventional methods, and massive waste materials will be generated, 
resulting in environment pollution $[29,30]$. With the deepening of consciousness throughout the whole society of environmental protection, economical and environmentally friendly methods are increasingly favored. The method of dry gel conversion (DGC) has advantages including higher zeolite yield, lower template agent usage, rapid crystallization, environment-friendliness and economic efficiency for zeolite synthesis [29].

The key factors influencing the synthesis of zeolite include the overall chemical composition of the reactant mixture and thermodynamic variables. Among these, silica source plays an important role in the synthesis process and also determines the morphology of the synthesized product [31]. Different silica are used as silica sources during the synthesis process of zeolite [32-34]. The effect of silica sources (natural silica nanoparticles derived from rice husk and commercial Ludox) on zeolite of $\mathrm{NaY}$ synthesis was been studied by Najat and coworkers [35]. NaY is the sodium type of Y zeolite. It has been found that adding natural silica from rice husk in both feedstock gel and seed gel for the preparation of $Y$ zeolite gel can produce a nanosilica catalyst and enhance the catalytic performance of catalytic cracking [35]. However, the effect of silica sources on the synthesis process of MFI zeolite has not yet been deeply investigated.

Silicalite-1, with an MFI topology structure, is an all-silica zeolite that only contains $\mathrm{Si}, \mathrm{O}$ and $\mathrm{H}$ in the framework. Silicalite- 1 has a pore diameter of about $5-6 \AA$ and possesses a 3D channel structure, with sinusoidal channels in the $x$-direction and straight channels in the y-direction. The two types of channels intersect with each other, forming a 3D porous structure [36,37]. Silicalite- 1 has high-temperature resistance, as well as strong hydrophobic and oil-wet properties, due to the absence of aluminum in the structure. Organic molecules such as arenes, short-chain alkanes and polyhydric alcohols can be absorbed by silicalite-1 [38]. Therefore, it has been extensively applied in catalysis and separation [39-41]. Since the supply of aluminum and other inorganic ions is avoided during the synthesis process of silicalite-1, high-quality crystals, rather than ZSM-5, are easier to synthesize. Silicalite- 1 is the best model for studying the synthesis mechanism, crystalline regulation, and control of MFI zeolite, as well as the dispersion and size of the particles. Meanwhile, research on silicalite- 1 synthesis provides references for the synthesis of a series of ZSM- 5 zeolite.

Hydrodeoxygenation (HDO) is a catalytic upgrading process, which has been considered to be the most effective method for bio-oil upgrading [42]. ZSM-5 with moderate acid intensity is a suitable acidic supplier for bio-oil upgrading, especially for lignin derived phenolic compounds upgrading.

In this work, in order to investigate the effect of silica sources on the synthesis of MFI zeolite, silicalite- 1 was synthesized using tetrapropylammonium hydroxide (TPAOH) as a template agent and silica of different particle sizes as silica sources. The dry gel conversion method was selected as the synthesis method of MFI zeolite in this study. The synthesis mechanisms of silicalite-1 derived from different silica sources were investigated. After careful adjustment of the silica sources, silicalite- 1 with nanoparticle size, smooth surface and coffin-like structure was synthesized. The synthesis mechanisms of silicalite- 1 with different silica sources were discussed. ZSM- 5 was synthesized by adding Al atoms to the raw materials in the dry gel conversion synthesis process. The physical and chemical characters of as-prepared samples were analyzed by X-ray diffraction (XRD), scanning electron microscope (SEM), $\mathrm{N}_{2}$-sorption, Fourier transform infrared spectroscopy (FTIR) and X-ray fluorescence spectrometer (XRF). The reaction activity of eugenol hydrodeoxygenation over ZSM-5 combined with $\mathrm{Pd} / \mathrm{C}$ catalysts was obtained.

\section{Results and Discussion}

\subsection{The Effect of Silica Sources and Synthesis Time on the Preparation of Silicalite-1}

To study the effect of silica sources on preparation of silicalite-1, fume silica with different primary particle sizes and spherical silica with a particle size of $300 \mathrm{~nm}$ were applied as silica sources in the synthesis process. 
In the process of synthesis, fume silica (AEROSIL200) with an average particle size of $12 \mathrm{~nm}$ was used as silica source, and crystallization time was changed from $1 \mathrm{~h}$ to $12 \mathrm{~h}$. The XRD spectra were obtained, as shown in Figure 1a. It can be seen that the characteristic diffraction peaks of silicalite-1 framework at around $7.97^{\circ}, 8.87^{\circ}, 23.17^{\circ}, 24.02^{\circ}$ and $24.46^{\circ}$ corresponded to the [101], [020], [501], [151] and [303] reflections, respectively [43]. After placing the mixture in the autoclave at $453 \mathrm{~K}$ for $1 \mathrm{~h}$, the characteristic peaks of MFI disappeared from the XRD spectrum. With the extending of crystallization time, characteristic peaks of MFI appeared in the XRD spectra, but with broad peaks existing between $23^{\circ}$ and $25^{\circ}$, which demonstrates that amorphous substances also existed in the sample. After crystallization at $453 \mathrm{~K}$ for $4 \mathrm{~h}$, the characteristic peaks of MFI were apparent and there was no significant difference among the XRD spectra of samples after crystallizing for $8 \mathrm{~h}$.

The FTIR spectra of materials synthesized using fume silica (AEROSIL200) as silica source with different crystallization times are shown in Figure 1b. The vibrational modes near 1100, 800 and $450 \mathrm{~cm}^{-1}$ are assigned to internal vibrations of $\mathrm{SiO}_{4}$. These kinds of vibration can also be observed in silica, quartz and cristobalite. Meanwhile, the vibrational modes near 1210 and $550 \mathrm{~cm}^{-1}$ were due to the asymmetric stretching of $\mathrm{SiO}_{4}$ and the double-ring tetrahedra vibration in the zeolite framework, respectively [44]. After crystallization for $2 \mathrm{~h}$, a very weak band at $550 \mathrm{~cm}^{-1}$ showed. It has been reported that a weak band at $550 \mathrm{~cm}^{-1}$ implies a low ordering of the material [44]. This result is in good agreement with the low crystallinity detected from XRD studies. With prolongation of the crystallization time, the strength of the band at $550 \mathrm{~cm}^{-1}$ increased significantly. After crystallization for $4 \mathrm{~h}$, the band near $1109 \mathrm{~cm}^{-1}$ was significant, which suggests that the internal linked antisymmetric stretching of Si-O-Si increased. Moreover, with the extending of crystallization time, the band near $1109 \mathrm{~cm}^{-1}$ became increasingly sharper, which indicates larger numbers of Si-O-Si bonds were formed.
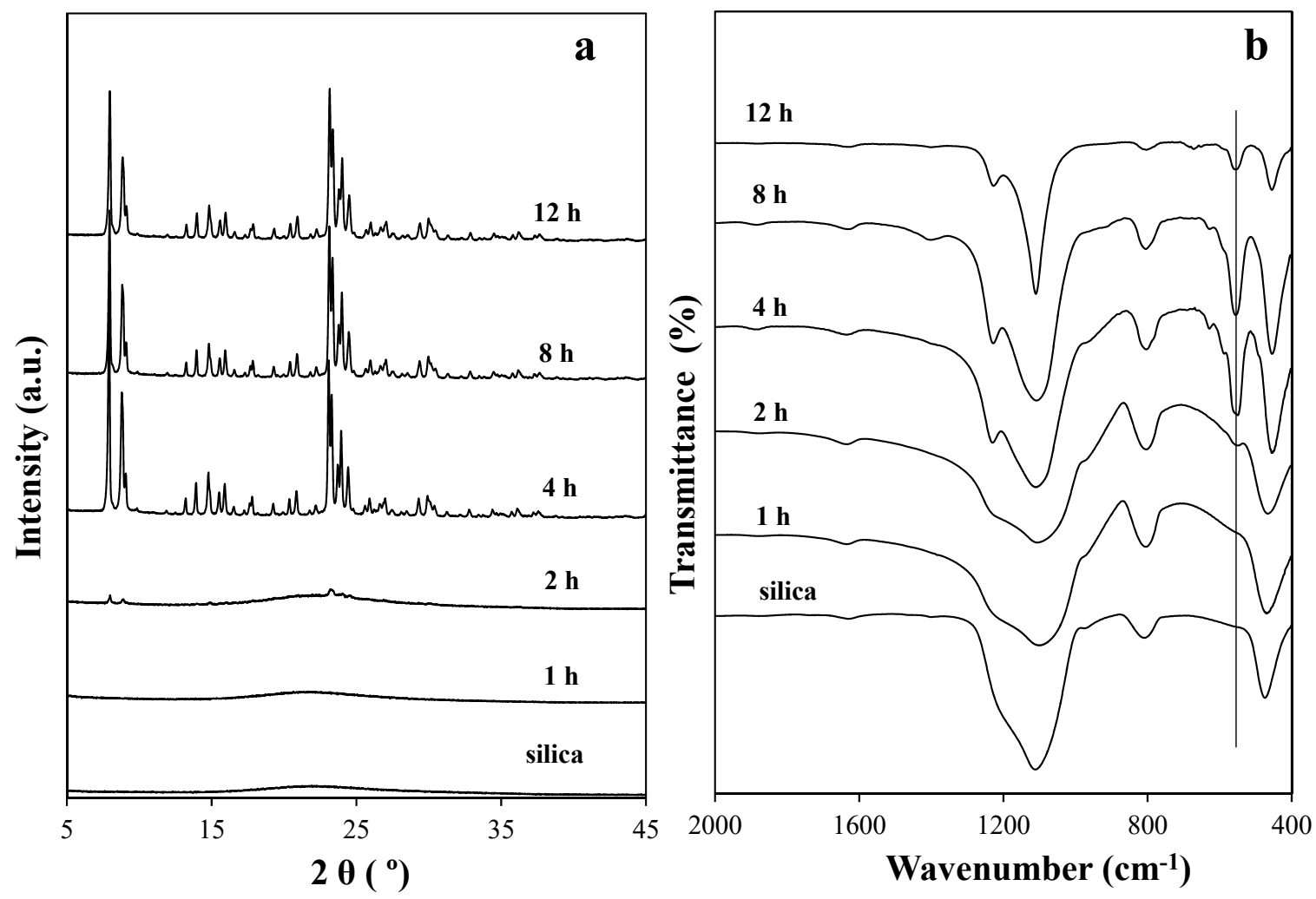

Figure 1. The XRD pattern (a) and FT-IR spectra (b) of silicalite-1 synthesized from silica with particle size of $12 \mathrm{~nm}$. 
When the crystallization time was $1 \mathrm{~h}$, the synthesized sample had no significant difference from the fume silica, according to the SEM images shown in Figure 2. When the crystallization time was prolonged to $2 \mathrm{~h}$, the morphology of sample still had no significant changes, and the sample was composed by aggregated particles in irregular shapes. However, it can be seen from the XRD spectra of the sample in Figure $1 \mathrm{a}$ that the characteristic peaks appeared after $2 \mathrm{~h}$, which reveals that silicalite- 1 particles were generated. When the crystallization time was prolonged to $4 \mathrm{~h}$, silicalite- 1 in regular morphology could be obtained. Furthermore, when the crystallization time was prolonged to $8 \mathrm{~h}$, silicalite-1 with uniform particles was obtained. When the crystallization time was extended to $12 \mathrm{~h}$, there was no significant change in the morphology of silicalite-1 samples.

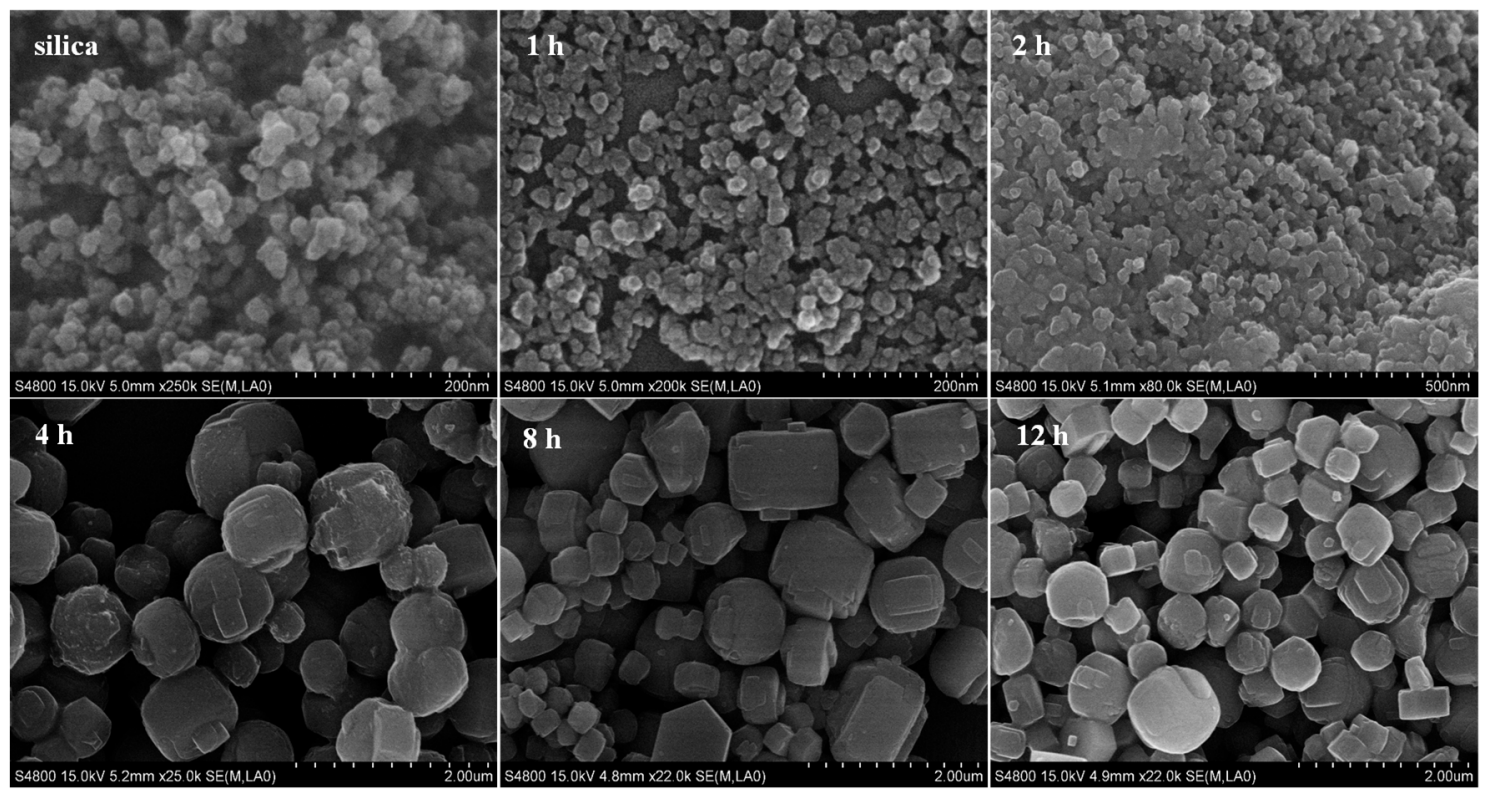

Figure 2. The SEM images of silicalite-1 synthesized from silica with particle size of $12 \mathrm{~nm}$.

Figure 3a shows the XRD patterns of samples synthesized with fume silica (AEROSIL380). After crystallization at $453 \mathrm{~K}$ for $2 \mathrm{~h}$, characterization peaks of MFI structure appeared, and the peak intensity was higher than that when using fume silica (AEROSIL200) as the silica source. This is possibly due to the fact that the fume silica of AEROSIL380 has a smaller particle size than fume silica of AEROSIL200, so that it is easier to combine the directing agent with silica source, and thus the MFI structure can be formed more easily.

Figure $3 \mathrm{~b}$ shows the FTIR spectra of silicalite- 1 synthesized by using fume silica AEROSIL380 with different synthesis time. After crystallization for $2 \mathrm{~h}$, a very weak band at $550 \mathrm{~cm}^{-1}$ showed the low ordering of the material, which is in good agreement with the low crystallinity detected from XRD studies. With the extension of the crystallization time, the strength of the band at $550 \mathrm{~cm}^{-1}$ increased significantly. After crystallization for $4 \mathrm{~h}$, a band near $1109 \mathrm{~cm}^{-1}$ was observed, which suggests that the internally linked antisymmetric stretching of Si-O-Si had increased. With the further increase of crystallization time, the band near $1109 \mathrm{~cm}^{-1}$ became sharper and sharper, which indicates that more and more Si-O-Si bonds had been formed. 

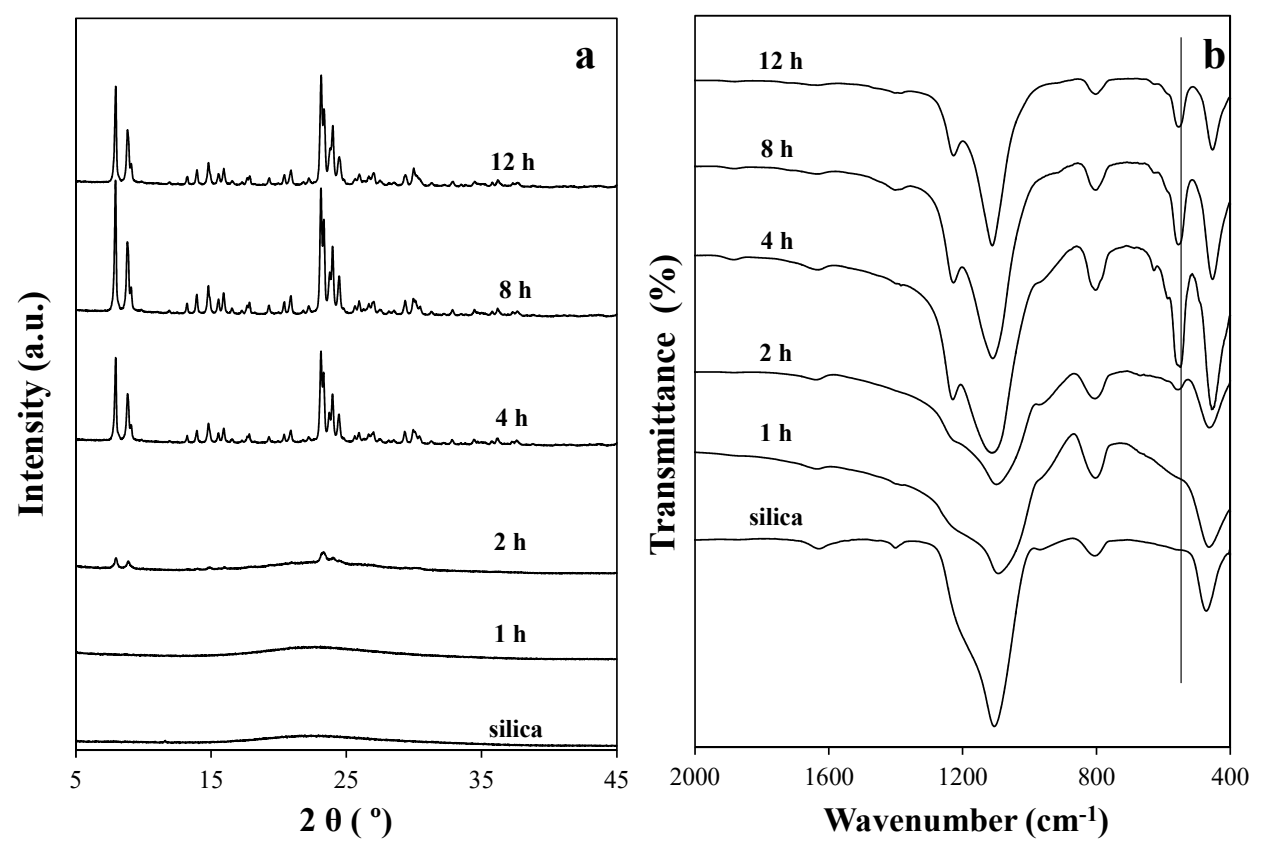

Figure 3. The XRD pattern (a) and FTIR (b) of silicalite-1 synthesized from silica with particle size of $7 \mathrm{~nm}$.

Unlike the synthesis of silicalite-1 using fume silica of AEROSIL200 as the silica source, the synthesis of silicalite- 1 using AEROSIL380 as silica source involved crystallization at $453 \mathrm{~K}$ for $2 \mathrm{~h}$, particles aggregated into bigger particles with the size larger than $200 \mathrm{~nm}$ (Figure 4). According to FTIR spectra and XRD patterns, it can be concluded that crystal of silicalie- 1 appeared after crystallization at $453 \mathrm{~K}$ for $2 \mathrm{~h}$, with small grains aggregated into big particles.

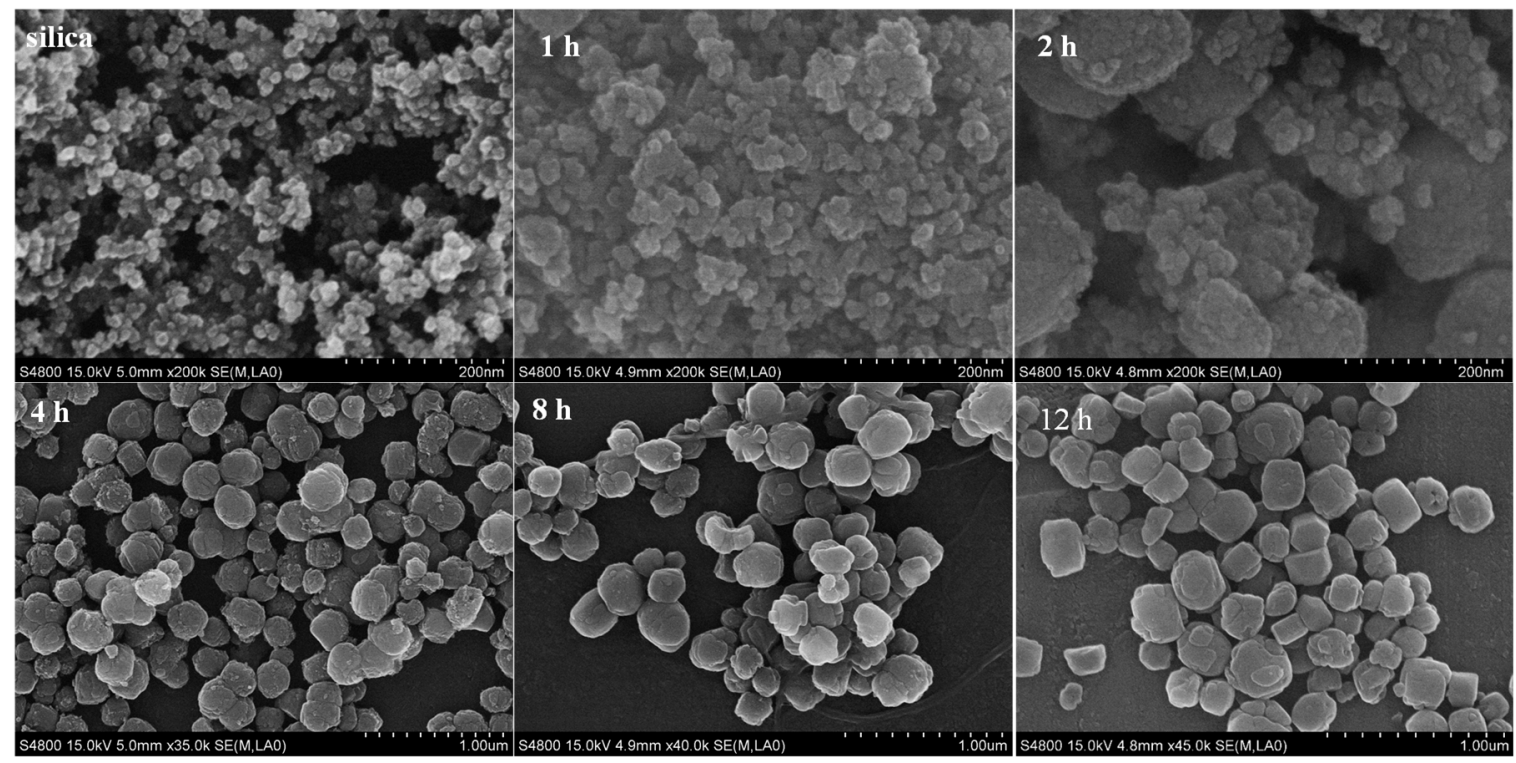

Figure 4. The SEM images of silicalite-1 synthesized from silica with particle size of $7 \mathrm{~nm}$.

Figure 5a shows the XRD patterns of samples synthesized with spherical silica (particle size of $300 \mathrm{~nm}$ ) as silica source. After crystallization at $453 \mathrm{~K}$ for $2 \mathrm{~h}$, the characterization peaks of MFI structure appeared. Moreover, the silicalite- 1 had $100 \%$ crystallization calculated based on the XRD pattern, and $71 \%$ crystallization calculated based on the FTIR spectrum. 

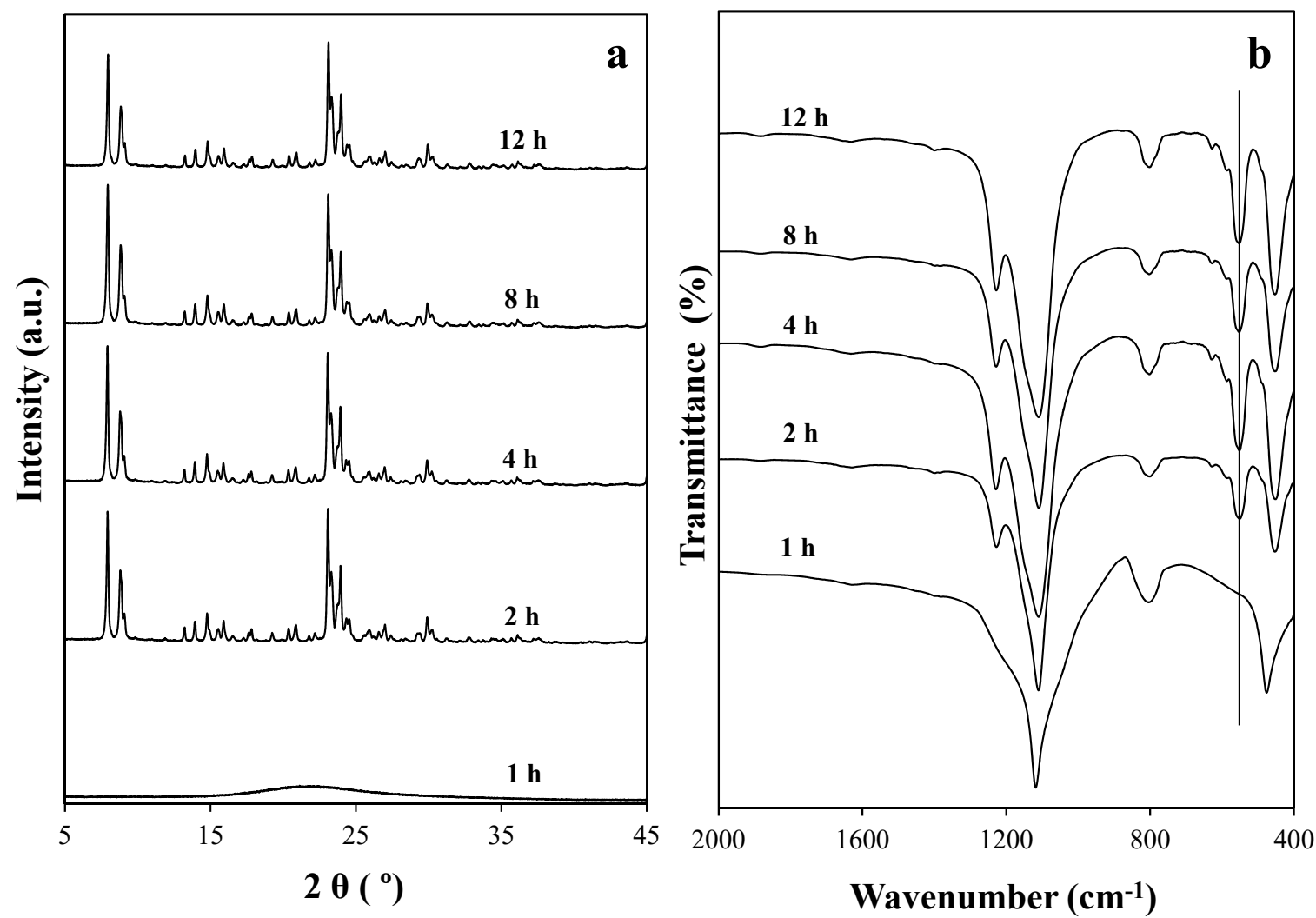

Figure 5. The XRD pattern (a) and FTIR (b) of silicalite-1 synthesized from silica spheres of $300 \mathrm{~nm}$.

As shown in Figure $5 \mathrm{~b}$, a very strong band at $550 \mathrm{~cm}^{-1}$ could be observed in the FTIR spectra of silicalite-1 when using spherical silica (particle size of $300 \mathrm{~nm}$ ) as the silica source and crystallizing for a time of $2 \mathrm{~h}$ or longer. At the same time, the band near $1109 \mathrm{~cm}^{-1}$ also appeared, which suggests that the internal linked antisymmetric stretching of $\mathrm{Si}-\mathrm{O}-\mathrm{Si}$ was strong. These results also demonstrate that the speed of crystallization using spherical silica with particle size of $300 \mathrm{~nm}$ as silica source was faster than that using the other two kinds of silica as silica source, which is well consistent with the result of the XRD studies.

According to Figure 6, after crystallization for $1 \mathrm{~h}$, the surface of the straw material presented a certain degree of damage when synthesizing silicalite- 1 using spherical silica as silica source. This indicates that there exist solutions of spherical silica at certain extent. Nevertheless, the overall spherical morphology still remained unchanged. High-quality silicalite-1 was synthesized after crystallization for $2 \mathrm{~h}$ at $453 \mathrm{~K}$, which is in concordance with the results of the XRD pattern. When extending the crystallization time to $12 \mathrm{~h}$, some cracks appeared on the crystal particles, which is possibly due to the desilication of silicalite-1 under an alkali system.

The crystallization degree of samples synthesized with different silica sources for different crystallization times was calculated by XRD patterns and FTIR spectra. The results are shown in Table 1 . The crystallization degrees were calculated according to the three strongest peaks in the scope of 22-25 of XRD patterns with reflections of [501], [151] and [303] and the bands of 550 and $450 \mathrm{~cm}^{-1}$ in the FTIR spectra $[44,45]$. The ZSM-5 purchased from the catalyst Plant of Nankai University (commercial code: NKF-5) was chosen as reference. 


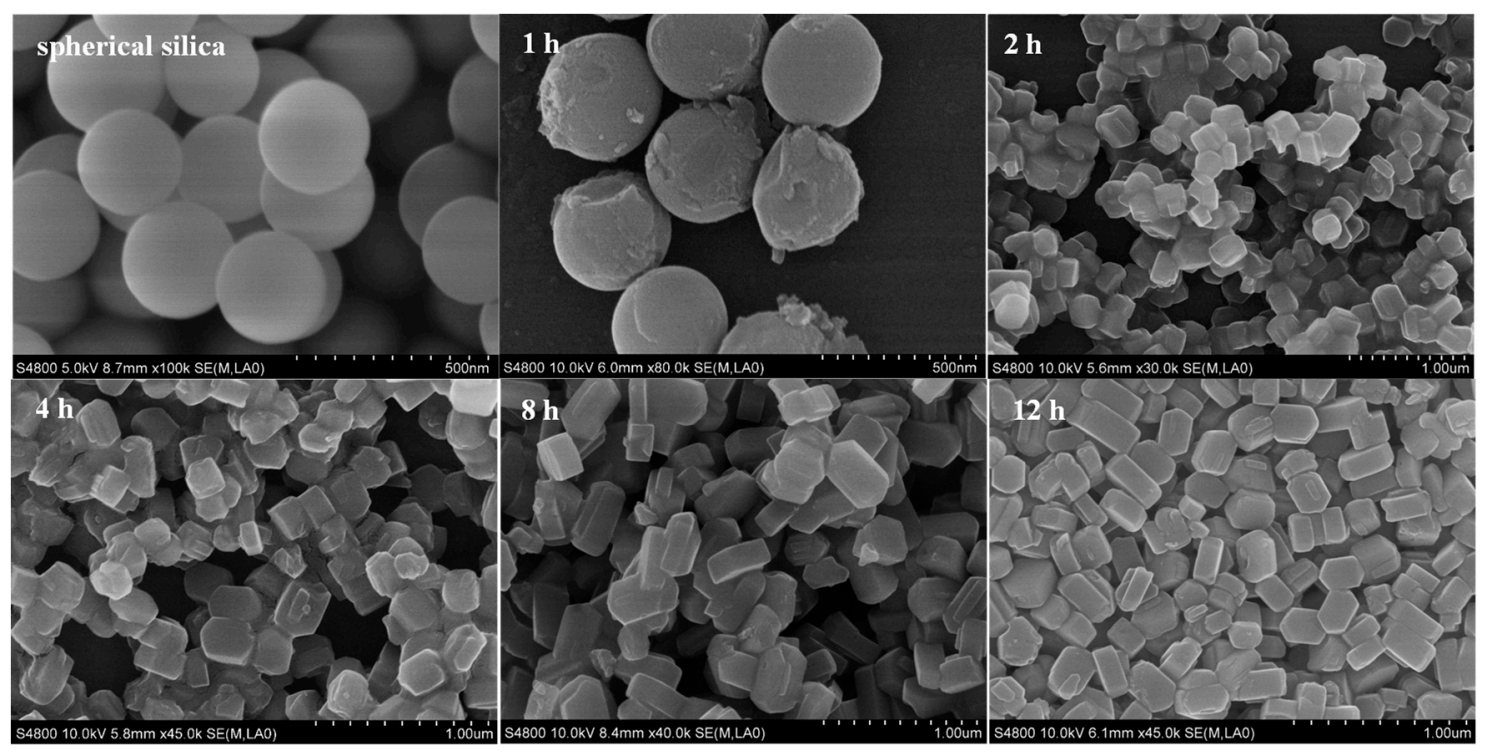

Figure 6. The SEM images of silicalite-1 synthesized from silica spheres of $300 \mathrm{~nm}$.

Table 1. Percent of crystallinities for silicalite-1 samples synthesized using different silica sources.

\begin{tabular}{|c|c|c|c|c|c|c|}
\hline \multirow{2}{*}{ Time } & \multicolumn{2}{|c|}{$200 \mathrm{~m}^{2} / \mathrm{g} \mathrm{SiO}_{2}$} & \multicolumn{2}{|c|}{$380 \mathrm{~m}^{2} / \mathrm{g} \mathrm{SiO}_{2}$} & \multicolumn{2}{|c|}{$300 \mathrm{~nm} \mathrm{SiO}{ }_{2}$ Spherical Silica } \\
\hline & IR & XRD & IR & XRD & IR & XRD \\
\hline $1 \mathrm{~h}$ & n.d. & n.d. & n.d. & n.d. & n.d. & n.d. \\
\hline $2 \mathrm{~h}$ & 7 & 16 & 47 & 17 & 71 & 100 \\
\hline $4 \mathrm{~h}$ & 83 & 100 & 90 & 74 & 73 & 99 \\
\hline
\end{tabular}

When using fume silica as silica source, with the extending of crystallization time, the crystallization degree of samples gradually increased and reached over $74 \%$ after crystallization for $4 \mathrm{~h}$ at $453 \mathrm{~K}$. In comparison, when using spherical silica as silica source, with the extending of crystallization time, the crystallization degree of silicalite- 1 reached to over $71 \%$ after $2 \mathrm{~h}$ of crystallization. Based on the results of SEM, silicalite-1 samples synthesized with spherical silica as source had better morphology compared with those synthesized with fume silica (with average particle sizes of 12 and $7 \mathrm{~nm}$ ) as silica source.

\subsection{The Effect of Spherical Silica Particle Size on Synthesis of Silicalite-1}

To study the effect of spherical silica size on the synthesis of silicalite-1, spherical silica with different particles sizes were synthesized and used as silica sources in the crystallization process.

The amounts of agents needed for synthesizing spherical silica with different sizes are showed in Table S1. The SEM images of spherical silica with particles size of 50, 100, 300 and $500 \mathrm{~nm}$ are as shown in Figure S1. All spherical silicas obtained have narrow particle size distributions.

Based on the results mentioned above, the synthesis time was set to $8 \mathrm{~h}$. The samples synthesized with spherical silica of different sizes as silica sources were characterized by XRD, as shown in Figure S2. As can be seen, the XRD patterns show straight basic line with no broad peaks, which indicates that silicalite-1 with a high degree of crystallization was obtained.

According to the SEM image in Figure 7, the morphology of samples can be analyzed. The particle size of silicalite-1 was around $200 \mathrm{~nm}$, which was significantly bigger than the size of spherical silica. This was due to the fact that a large quantity of spherical silica with small particle sizes were thoroughly decomposed, leaving small amounts of spherical silica in the solution. Therefore, there was a mass of nuclear phase present in the solution, while there was little spherical silica serving as a silica source for the growth of silicalite-1. With the growth of silicalite-1, nuclear phases joined with others, resulting in bigger silicalite- 1 crystals. The aggregation of silicalite- 1 synthesized with spherical silica (particle 
size of $50 \mathrm{~nm}$ ) as the silica source was basically a consequence of the aggregation of spherical silica. With the particle size of spherical silica increasing from 50 to $300 \mathrm{~nm}$, the morphology of silicalite- 1 became more and more regular, and finally coffin-like silicalite- 1 was obtained. As the particle size of spherical silica further increased to $500 \mathrm{~nm}$, there were no significant changes in the morphology of silicalite-1.

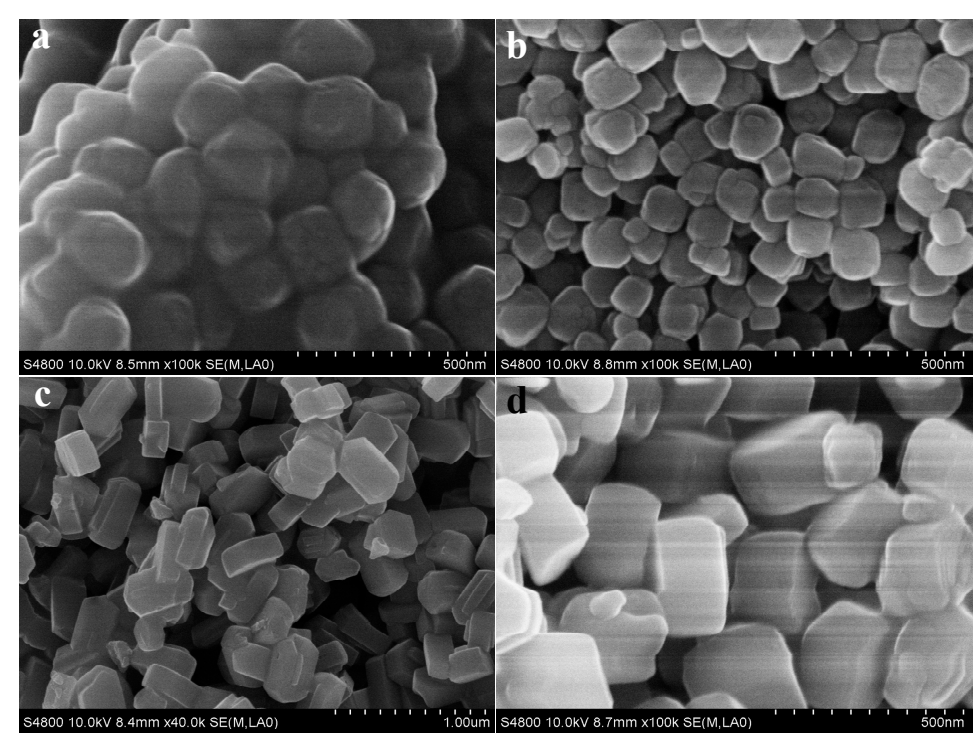

Figure 7. SEM images of silicalite-1 synthesized from silica spheres with various particle sizes of (a), $50 \mathrm{~nm}$; (b), $100 \mathrm{~nm}$; (c), $300 \mathrm{~nm}$; (d), $500 \mathrm{~nm}$.

As is depicted above, the particle size of the silica source can impact the synthesis time of silicalite-1. Using spherical silica as the silica source can result in samples with better properties than using fume silica as the silica source, which is probably due to the larger particle size of spherical silica. When the silicalite- 1 was synthesized using fume silica $(7-12 \mathrm{~nm})$ as the silica source, the silica nucleated automatically and dispersed in the solution, and then the smaller crystals dispersed in the solution jointed with each other, resulting in bigger silicalite- 1 crystals due to the high surface energy of the small crystals. In contrast, when the silicalite- 1 was synthesized using spherical silica as the silica source, the silica nucleated automatically on the surface of spherical silica due to the large particle size of the spherical silica, supplying silica source continuously. As a result, the formation of smaller crystals was reduced, and the joint time during the silicalite- 1 synthesis was shortened, and thus the total time required for silicalite-1 growth was shortened as well.

The schematic diagram of silicalite- 1 formation using different silicon sources is speculated to be as shown in Figure 8. As for fume silica as silica source for MFI zeolite synthesis, due to the small particle sizes of fume silica sources $(7-12 \mathrm{~nm})$, the fume silica is quickly hydrolyzed into nuclear phases and homogeneously dispersed in the alkaline solution. Then these nuclear phases are aggregated, and crystals of MFI zeolite are formed and grow gradually. However, when spherical silica with particle sizes higher than $50 \mathrm{~nm}$ are used as the silica source for MFI zeolite synthesis, the larger particle sizes of spherical silica cause crystallization of the nuclear phases and hydrolyzation of the silica source to co-exist on the surface of the spherical silica. As time goes by, the volume of nuclear phases gradually increases and the spherical silica disappears, finally leading to the formation of MFI crystal. It is indicated that the dispersion of nuclear phases in the alkaline solution is the most decisive step for the formation of MFI. Compared with the nuclear phases being dispersed independently in the solution when using fume silica as silicon source, the nuclear phases when using spherical silica as silicon source were close to each other and polymerized with each other faster, leading to a shortened time of crystallization for MFI zeolite. Meanwhile, the regular shape of the silicon source also had a significant impact on the morphology of as-prepared MFI zeolite. 


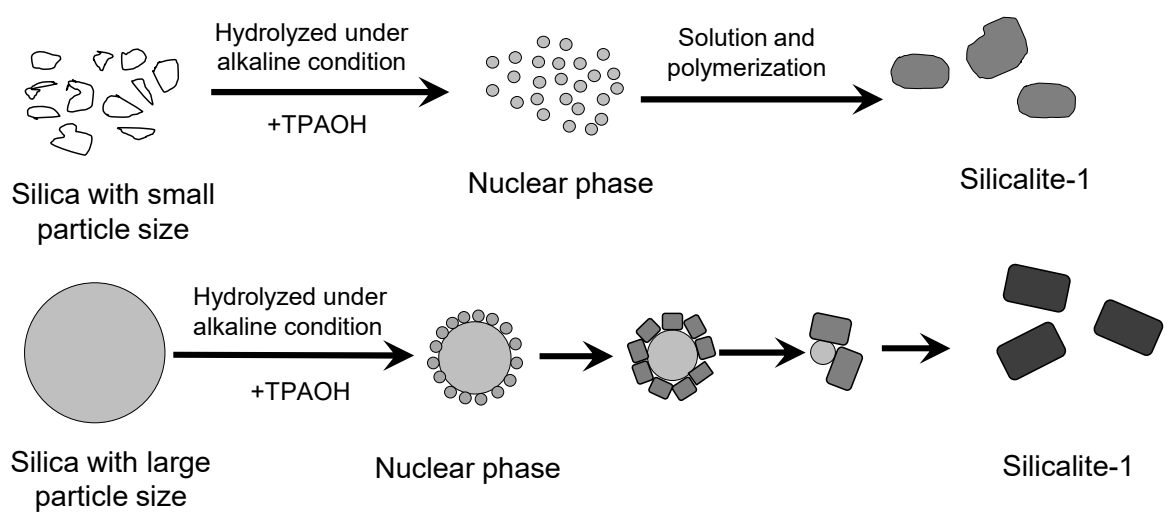

Figure 8. Schematic diagram of silicalite-1 growth using silica sources with different particle sizes during the synthesis process.

\subsection{Synthesis of ZSM-5 and Catalytic Performance}

Based on the above experiments, $\mathrm{Al}$ atoms were added to obtain ZSM-5 zeolite. Silica with a particle size of $300 \mathrm{~nm}$ was selected as the silica source, and then thermal treatment was conducted at $453 \mathrm{~K}$ for 1 day to obtain ZSM- 5 samples. The XRD spectrum and SEM image of ZSM-5 are shown in Figure 9. The obtained ZSM-5 samples had small particle sizes, and pure and high crystallization of MFI structure was obtained based on the SEM image and XRD spectrum of ZSM-5. The XRF result showed that the actual $\mathrm{Si}$ to $\mathrm{Al}$ ratio of ZSM-5 was 38. The main products after eugenol hydrodeoxygenation in the aqueous phase over Pt/C-based HZSM- 5 catalysts were hydrocarbon, 2-methoxy-4-propyl-cyclohexanol, propyl-cyclohexanone in liquid phase and methanol in gas phase. The carbon balance of the product was $91 \%$. High hydrocarbon selectivity $(73.8 \%)$ and eugenol conversion $(96.5 \%)$ were obtained from the HDO reaction when using the synthesized ZSM-5 as supporter and acidic site supplier. This result is higher than those reported in the references $[46,47]$. The selectivity of hydrocarbon is lower than $50 \%$, when using Pd/C and HZSM- 5 as the catalysts for eugenol hydrodeoxygenation in aqueous phase [47]. However, the morphology of ZSM-5 was irregular, and needs to be improved in the future research.
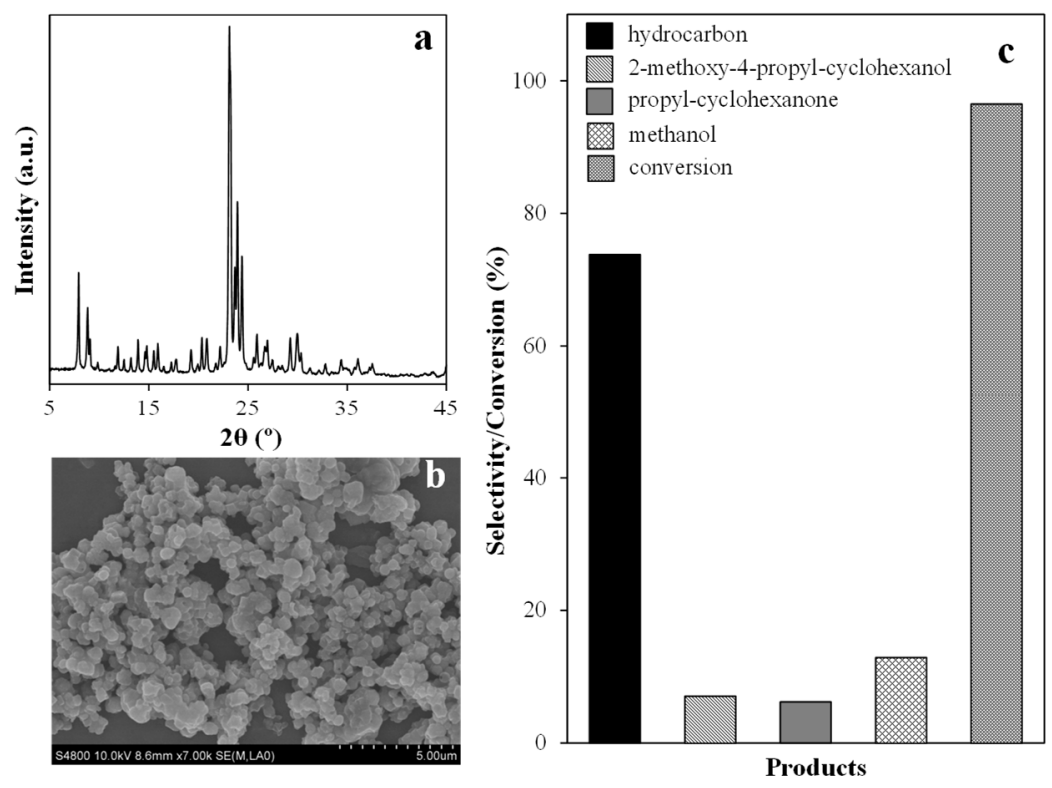

Figure 9. The XRD spectrum (a) and SEM image (b) of ZSM-5 synthesized from silica spheres, and the catalytic performance of APR hydrodeoxygenation over Pd/C-based HZSM-5 catalysts (c). 


\section{Experimental}

\subsection{Chemicals}

The chemical products used in this experiment include ammonium hydroxide solution (25-28\% $\mathrm{NH}_{3} \cdot \mathrm{H}_{2} \mathrm{O}$, Sinopharm Chemical Reagent Shanghai Co., Ltd., Shanghai, China), tetraethoxysilane (TEOS, Sinopharm Chemical Reagent Shanghai Co., Ltd., Shanghai, China), ethanol (Sinopharm Chemical Reagent Shanghai Co., Ltd., Shanghai, China), n-propanol (Sinopharm Chemical Reagent Shanghai Co., Ltd., Shanghai, China), fumed silica of AEROSIL200 ( $99.8 \%$, average particle size of $7 \mathrm{~nm}$ ) and AEROSIL380 (99.8\%, average particle size of $12 \mathrm{~nm}$ ) from Evonik Degussa Specialty Chemicals Shanghai Co., Ltd., (Shanghai, China), sodium aluminate $\left(\mathrm{NaAlO}_{2}\right.$, AR, from Aladdin, Shanghai, China) and TPAOH (25\% in water, Tianjin Guangfu Fine Chemical Research Institute, Tianjin, China).

\subsection{Synthesis Process}

The general synthesis method for spherical silica can be described as follows: firstly, a certain volume of $28 \% \mathrm{NH}_{3} \cdot \mathrm{H}_{2} \mathrm{O}$ and alcohol or n-propanol were mixed with a certain volume of deionized water, resulting in a mixed solution named as solution A. Then, a quantity of TEOS and alcohol, methyl alcohol or n-propanol were mixed, resulting in mixed solution is named as solution B. Then, the obtained solution B was poured into solution A before magnetic stirring at high speed for $2 \mathrm{~h}$ at room temperature. Finally, the mixture was centrifuged, washed with ethanol three times and dried at $333 \mathrm{~K}$ overnight.

The synthesis process of silicalite- 1 can be described as follows. Firstly, $20 \mathrm{~mL}$ of $25 \% \mathrm{TPAOH}$ solution and $10 \mathrm{~g}$ of silica source were put into a $50 \mathrm{~mL}$ beaker, and then mixed evenly with a glass rod. The beaker was sealed with para film and was placed on the table at room temperature for $1 \mathrm{~h}$. Then, the excess water was absorbed using filter paper, and the obtained mixture was put in the oven at $313 \mathrm{~K}$ for $1.5 \mathrm{~h}$. Subsequently, the mixture was transferred to an autoclave, sealed and heated at $453 \mathrm{~K}$ for a certain period of time under static conditions. After cooling to room temperature, the mixture was filtered and washed with distilled water three times. The solid precipitates were collected and dried at $353 \mathrm{~K}$ overnight. Finally, the template was removed by calcining the solid precipitates in a muffle furnace up to $823 \mathrm{~K}$ at a rate of $3 \mathrm{~K} / \mathrm{min}$, and then kept at this temperature for $5 \mathrm{~h}$. The synthesis procedure for ZSM-5 was the same as shown above for silicalite-1, except that TPAOH was added to the solution. HZSM- 5 was synthesized by adding $0.054 \mathrm{~g}(0.66 \mathrm{mmol})$ of sodium aluminate into the synthesis process of MFI and silica with a particle size of $300 \mathrm{~nm}$ was chosen as the silica source. The thermal treatment of HZSM- 5 was conducted at $453 \mathrm{~K}$ for 1 day.

\subsection{Characterization}

XRD measurements were carried out on a Bruker D8 Advance powder diffractometer, using $\mathrm{Cu}$ $\mathrm{K} \alpha$ radiation (wavelength $\lambda=1.5147 \AA, 40 \mathrm{kV}, 40 \mathrm{~mA}$ ), with a step size of $0.02^{\circ}(2 \theta)$ and 2 s per step over the $2 \theta$ ranging from $5^{\circ}$ to $45^{\circ}$. The XRD crystallinities of the silicatlite- 1 samples were determined by comparison of the intensities of the four major reflections in region of $22.5^{\circ}$ to $24^{\circ}$ relative to those of a reference NKF-5 with $\mathrm{Si} / \mathrm{Al}$ ratio as 50 [48]. Si and Al contents of ZSM-5 were determined by XRF (Axios PW4400, Panalytical, The Netherlands). SEM analysis was conducted on a Hitachi S-4800 electronic microscope at $200 \mathrm{kV}$. Nitrogen adsorption-desorption isotherms were measured at $77 \mathrm{~K}$ on a micromeritics ASAP 2020 sorptometer. FTIR spectra were recorded on a Nicolet 6700 with a resolution less than $0.4 \mathrm{~cm}^{-1}$ and signal-to-noise ratio of 50000:1. The samples were mixed with $\mathrm{KBr}$ and pressed into flakes before testing. The intensity ratio of the 550 and $450 \mathrm{~cm}^{-1}$ band, namely the $I_{550} / I_{450}$ ratio, is used to assess the crystallinity of silicalite- 1 samples. 


\subsection{HDO of Eugenol}

Eugenol $(1.2 \mu \mathrm{mol}), \mathrm{Pd} / \mathrm{C}(0.03 \mathrm{~g})$ and HZSM-5 $(0.5 \mathrm{~g})$ were loaded into a stainless-steel autoclave $(100 \mathrm{~mL})$ with distilled water $(20 \mathrm{~mL})$. The reactor was flushed with $\mathrm{H}_{2}$ three times, and the pressure was adjusted to $2 \mathrm{Mpa}$ with $\mathrm{H}_{2}$. Then, the temperature was increased to $513 \mathrm{~K}$ while maintaining (700 rpm), and the reaction was held at $513 \mathrm{~K}$ for $3 \mathrm{~h}$. After the reactor was quenched with ice to room temperature, the aqueous and gas phase were collected directly, and the organic mixture was extracted by ethyl acetate. The organic and aqueous phases were both quantitatively analyzed by gas chromatography-mass spectrometry (GC-MS; Agilent 7890A-Agilent 5975C, Santa Clara, CA, USA) equipped with a capillary column (HP-5; $30 \mathrm{~m} \times 250 \mu \mathrm{m})$.

\section{Conclusions}

High-quality coffin-like silicalite-1 was synthesized via dry gel conversion method by using silica sphere with a particle size of $300 \mathrm{~nm}$ as the silica source, with the crystallization time being decreased to $2 \mathrm{~h}$. The time for crystallization was curtailed by using silica spheres instead of fume silica (AEROSIL200 and AEROSIL380) as the silica source during the synthesis process of MFI. Silica spheres with a particle size of $300 \mathrm{~nm}$ is much better for using as silica source during the synthesis process of MFI than silica spheres with larger particle size or fume silica. The formation mechanisms of silicalite- 1 using silica sources with different particle sizes were concluded. The particle size of silica sources and the polymerization speed of silica sources were two key factors impacting the sizes of the final product of silicalite-1. ZSM- 5 samples with $\mathrm{Si}$ to $\mathrm{Al}$ ratio of 38 were obtained by the DGC method. The catalytic activity of ZSM- 5 with $\mathrm{Pd} / \mathrm{C}$ as catalyst for eugenol hydrodeoxygenation in aqueous phase was investigated. High hydrocarbon selectivity (73.8\%) and eugenol conversion (96.5\%) were obtained from the HDO reaction when using the synthesized ZSM- 5 as supporter and acidic sites supplier.

Supplementary Materials: The following are available online at http:/ /www.mdpi.com/2073-4344/9/1/13/s1, Table S1. Amount of agents needed for spherical silica during the synthesis process, Figure S1. SEM images of silica sphere with different particle sizes, Figure S2. XRD patterns of silicalite-1 synthesized with silica spheres of different particle sizes.

Author Contributions: Data Curation, J.L.; Methodology, C.W.; Writing-Original Draft Preparation, X.L.; Writing—review \& Editing, J.Z.

Acknowledgments: This work is financially supported by National Natural Science Foundation of China through project (grant number: 51602215 and 41502131), the Fundamental Research Funds for the Central Universities (grant number: 18CX02101A) and National Science and Technology Major Project (grant number: 2016ZX05014-0004-07).

Conflicts of Interest: The authors declare no conflict of interest. The funders had no role in the design of the study; in the collection, analyses, or interpretation of data; in the writing of the manuscript, or in the decision to publish the results.

\section{References}

1. Zhou, W.; Zhang, S.Y.; Hao, X.Y.; Guo, H.; Zhang, C.; Zhang, Y.Q.; Liu, S.X. MFI-type boroaluminosilicate: A comparative study between the direct synthesis and the templating method. J. Solid State Chem. 2006, 179, 855-865. [CrossRef]

2. Sarmah, B.; Satpati, B.; Srivastava, R. Highly efficient and recyclable basic mesoporous zeolite catalyzed condensation, hydroxylation, and cycloaddition reactions. J. Colloid. Interface Sci. 2017, 493, 307-316. [CrossRef] [PubMed]

3. Akhmetzyanova, U.; Opanasenko, M.; Horacek, J.; Montanari, E.; Cejka, J.; Kikhtyanin, O. Zeolite supported palladium catalysts for hydroalkylation of phenolic model compounds. Micropous Mesoporous Mater. 2017, 252, 116-124. [CrossRef]

4. Silva, A.F.; Fernandes, A.; Antunes, M.M.; Neves, P.; Rocha, S.M.; Ribeiro, M.F.; Pillinger, M.; Ribeiro, J.; Silva, C.M.; Valente, A.A. TUD-1 type aluminosilicate acid catalysts for 1-butene oligomerisation. Fuel 2017, 209, 371-382. [CrossRef] 
5. Grenev, I.V.; Gavrilov, V.Y. Calculation of adsorption properties of aluminophosphate and aluminosilicate zeolites. Adsorption 2017, 23, 903-915. [CrossRef]

6. Moreno-Recio, M.; Jimenez-Morales, I.; Arias, P.L.; Santamaria-Gonzalez, J.; Maireles-Torres, P. The Key Role of Textural Properties of Aluminosilicates in the Acid-Catalysed Dehydration of Glucose into 5-Hydroxymethylfurfural. Chemistryselect 2017, 2, 2444-2451. [CrossRef]

7. Rillig, M.C.; Wagner, M.; Salem, M.; Antunes, P.M.; George, C.; Ramke, H.G.; Titirici, M.M.; Antonietti, M. Material derived from hydrothermal carbonization: Effects on plant growth and arbuscular mycorrhiza. Appl. Soil Ecolog. 2010, 45, 238-242. [CrossRef]

8. Al-Jubouri, S.M.; Holmes, S.M. Hierarchically porous zeolite $\mathrm{X}$ composites for manganese ion-exchange and solidification: Equilibrium isotherms, kinetic and thermodynamic studies. Chem. Eng. J. 2017, 308, 476-491. [CrossRef]

9. Losch, P.; Pinar, A.B.; Willinger, M.G.; Soukup, K.; Chavan, S.; Vincent, B.; Pale, P.; Louis, B. H-ZSM-5 zeolite model crystals: Structure-diffusion-activity relationship in methanol-to-olefins catalysis. J. Catal. 2017, 345, 11-23. [CrossRef]

10. Hernandez-Tamargo, C.E.; Roldan, A.; de Leeuw, N.H. A density functional theory study of the structure of pure-silica and aluminium-substituted MFI nanosheets. J. Solid State Chem. 2016, 237, 192-203. [CrossRef]

11. Barakov, R.; Shcherban, N.; Yaremov, P.; Solomakha, V.; Vyshnevskyy, A.; Ilyin, V. Low-temperature synthesis, structure, sorption properties and acidity of zeolite ZSM-5. J. Porous Mater. 2016, 23, 517-528. [CrossRef]

12. Mi, S.; Wei, T.; Sun, J.; Liu, P.; Li, X.; Zheng, Q.; Gong, K.; Liu, X.; Gao, X.; Wang, B.; Zhao, H.; Liu, H.; Shen, B. Catalytic function of boron to creating interconnected mesoporosity in microporous $\mathrm{Y}$ zeolites and its high performance in hydrocarbon cracking. J. Catal. 2017, 347, 116-126. [CrossRef]

13. Chung, K.H.; Park, H.; Jeon, K.J.; Park, Y.K.; Jung, S.C. Microporous Zeolites as Catalysts for the Preparation of Decyl Glucoside from Glucose with 1-Decanol by Direct Glucosidation. Catalysts 2016, 6, 216. [CrossRef]

14. Menoufy, M.F.; Nadia, A.E.; Ahmed, H.S. Catalytic Dewaxing for Lube Oil Production. Petrol. Sci. Technol. 2009, 27, 568-574. [CrossRef]

15. Xin, H.; Li, X.; Fang, Y.; Yi, X.; Hu, W.; Chu, Y.; Zhang, F.; Zheng, A.; Zhang, H.; Li, X. Catalytic dehydration of ethanol over post-treated ZSM-5 zeolites. J. Catal. 2014, 312, 204-215. [CrossRef]

16. Li, X.; Xing, J.; Zhou, M.; Zhang, H.; Huang, H.; Zhang, C.; Song, L.; Li, X. Influence of crystal size of HZSM-5 on hydrodeoxygenation of eugenol in aqueous phase. Catal. Commun. 2014, 56, 123-127. [CrossRef]

17. Xie, J.; Zhuang, W.; Wei, Z.; Ning, Y.; Yu, Z.; Ju, W. Construction of Acid-Base Synergetic Sites on Mg-bearing BEA Zeolites Triggers the Unexpected Low-Temperature Alkylation of Phenol. Chemcatchem 2017, 9, 1076-1083. [CrossRef]

18. Wang, Y.; Wu, J.; Wang, S. Hydrodeoxygenation of bio-oil over Pt-based supported catalysts: Importance of mesopores and acidity of the support to compounds with different oxygen contents. Rsc Adv. 2013, 3, 12635-12640. [CrossRef]

19. Beiragh, H.H.; Omidkhah, M.; Abedini, R.; Khosravi, T.; Pakseresht, S. Synthesis and characterization of poly (ether-block-amide) mixed matrix membranes incorporated by nanoporous ZSM-5 particles for CO2/CH4 separation. Asia-Pac. J. Chem. Eng. 2016, 11, 522-532. [CrossRef]

20. Lakhane, M.; Khairnar, R.; Mahabole, M. Metal oxide blended ZSM-5 nanocomposites as ethanol sensors. Bull. Mater. Sci. 2016, 39, 1483-1492. [CrossRef]

21. Pande, H.B.; Parikh, P.A. Novel Application of ZSM-5 Zeolite: Corrosion-Resistant Coating in Chemical Process Industry. J. Mater. Eng. Perform. 2013, 22, 190-199. [CrossRef]

22. McDonnell, A.M.P.; Beving, D.; Wang, A.J.; Chen, W.; Yan, Y.S. Hydrophilic and antimicrobial zeolite coatings for gravity-independent water separation. Adv. Funct. Mater. 2005, 15, 336-340. [CrossRef]

23. Jiao, K.; Xu, X.; Lv, Z.; Song, J.; He, M.; Gies, H. Synthesis of nanosized Silicalite-1 in F- media. Micropous Mesoporous Mater. 2016, 225, 98-104. [CrossRef]

24. Mohammed, M.A.A.; Salmiaton, A.; Azlina, W.A.K.G.W.; Amran, M.S.M.; Fakhru'l-Razi, A.; Taufiq-Yap, Y.H. Hydrogen rich gas from oil palm biomass as a potential source of renewable energy in Malaysia. Renew. Sustain. Energy Rev. 2011, 15, 1258-1270. [CrossRef]

25. Cimenler, U.; Joseph, B.; Kuhn, J.N. Hydrocarbon steam reforming using Silicalite-1 zeolite encapsulated Ni-based catalyst. Aiche J. 2017, 63, 200-207. [CrossRef] 
26. Ge, C.; Li, Z.; Chen, G.; Qin, Z.; Li, X.; Dou, T.; Dong, M.; Chen, J.; Wang, J.; Fan, W. Kinetic study of vapor-phase Beckmann rearrangement of cyclohexanone oxime over silicalite-1. Chem. Eng. Sci. 2016, 153, 246-254. [CrossRef]

27. Kabalan, I.; Rioland, G.; Nouali, H.; Lebeau, B.; Rigolet, S.; Fadlallah, M.B.; Toufaily, J.; Hamiyeh, T.; Daou, T.J. Synthesis of purely silica MFI-type nanosheets for molecular decontamination. Rsc Adv. 2014, 4, 37353-37358. [CrossRef]

28. Sanhoob, M.A.; Muraza, O. Synthesis of silicalite-1 using fluoride media under microwave irradiation. Microporous Mesoporous Mater. 2016, 233, 140-147. [CrossRef]

29. Han, S.W.; Kim, J.; Ryoo, R. Dry-gel synthesis of mesoporous MFI zeolite nanosponges using a structure-directing surfactant. Microporous Mesoporous Mater. 2017, 240, 123-129. [CrossRef]

30. Meng, X.; Xiao, F.S. Green Routes for Synthesis of Zeolites. Chem. Rev. 2014, 114, 1521-1543. [CrossRef]

31. Mintova, S.; Valtchev, V. Effect of the silica source on the formation of nanosized silicalite-1: An in situ dynamic light scattering study. Micropous Mesoporous Mater. 2002, 55, 171-179. [CrossRef]

32. Pan, F.; Lu, X.; Zhu, Q.; Zhang, Z.; Yan, Y.; Wang, T.; Chen, S. Direct synthesis of HZSM-5 from natural clay. J. Mater. Chem. A 2015, 3, 4058-4066. [CrossRef]

33. Jesudoss, S.K.; Vijaya, J.J.; Kaviyarasu, K.; Rajan, P.I.; Narayanan, S.; Kennedy, L.J. In vitro anti-cancer activity of organic template-free hierarchical $\mathrm{M}(\mathrm{Cu}, \mathrm{Ni})$-modified ZSM-5 zeolites synthesized using silica source waste material. J. Photochem. Photobiol. B. 2018, 186, 178-188. [CrossRef] [PubMed]

34. Khoshbin, R.; Oruji, S.; Karimzadeh, R. Catalytic cracking of light naphtha over hierarchical ZSM-5 using rice husk ash as silica source in presence of ultrasound energy: Effect of carbon nanotube content. Adv. Powder Technol. 2018, 29, 2176-2187. [CrossRef]

35. Saleh, N.J.; Al-Zaidi, B.Y.S.; Sabbar, Z.M. A Comparative Study of Y Zeolite Catalysts Derived from Natural and Commercial Silica: Synthesis, Characterization, and Catalytic Performance. Arab. J. Sci. Eng. 2018, 43, 5819-5836. [CrossRef]

36. Bai, P.; Tsapatsis, M.; Siepmann, J.I. Multicomponent Adsorption of Alcohols onto Silicalite-1 from Aqueous Solution: Isotherms, Structural Analysis, and Assessment of Ideal Adsorbed Solution Theory. Langmuir 2012, 28, 15566-15576. [CrossRef] [PubMed]

37. Qi, J.; Zhao, T.; Xu, X.; Li, F.; Sun, G. Hydrothermal synthesis of size-controlled silicalite-1 crystals. J. Porous Mater. 2011, 18, 509-515. [CrossRef]

38. Sanchez-Flores, N.A.; Solache, M.; Olguin, M.T.; Legaspe, J.; Pacheco-Malagon, G.; Saniger, J.M.; Martinez, E.; Bulbulian, S.; Fripiat, J.J. Silicalite-1, an adsorbent for 2-, 3-, and 4-chlorophenols. Water Sci. Technol. 2012, 66, 247-253. [CrossRef]

39. Shi, L.; Song, X.; Liu, G.; Guo, H. Effect of Catalyst Preparation on Hydroisomerization of n-Heptane over Pt/Silicalite-1. Catal. Lett. 2017, 147, 2549-2557. [CrossRef]

40. Amiri, H.; Charkhi, A.; Moosavian, M.A.; Ahmadi, S.J.; Nourian, H. Performance improvement of PDMS/PES membrane by adding silicalite-1 nanoparticles: Separation of xenon and krypton. Chem. Pap. 2017, 71, 1587-1596. [CrossRef]

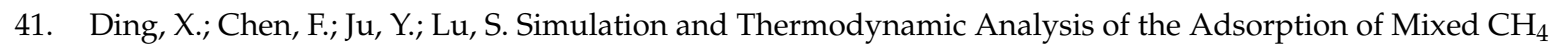
and N-2 on Silicalite-1 Molecular Sieve. J. Nanosci. Nanotechnol. 2017, 17, 6732-6737. [CrossRef]

42. Moreira, R.; Ochoa, E.; Pinilla, J.L.; Portugal, A.; Suelves, I. Liquid-Phase Hydrodeoxygenation of Guaiacol over Mo2C Supported on Commercial CNF. Effects of Operating Conditions on Conversion and Product Selectivity. Catalysts 2018, 8, 127. [CrossRef]

43. Barot, S.; Nawab, M.; Bandyopadhyay, R. Alkali metal modified nano-silicalite-1: An efficient catalyst for transesterification of triacetin. J. Porous Mater. 2016, 23, 1197-1205. [CrossRef]

44. Xue, T.; Wang, Y.M.; He, M.Y. Facile synthesis of nano-sized $\mathrm{NH}_{4}-\mathrm{ZSM}-5$ zeolites. Micropous Mesoporous Mater. 2012, 156, 29-35. [CrossRef]

45. Xin, H.; Koekkoek, A.; Yang, Q.; van Santen, R.; Li, C.; Hensen, E.J.M. A hierarchical Fe/ZSM-5 zeolite with superior catalytic performance for benzene hydroxylation to phenol. Chem. Commun. 2009, 7590-7592. [CrossRef] [PubMed]

46. Zhang, C.; Xing, J.; Song, L.; Xin, H.; Lin, S.; Xing, L.; Li, X. Aqueous-phase hydrodeoxygenation of lignin monomer eugenol: Influence of $\mathrm{Si} / \mathrm{Al}$ ratio of HZSM-5 on catalytic performances. Catal. Today 2014, 234, 145-152. [CrossRef] 
47. Xing, J.; Song, L.; Zhang, C.; Zhou, M.; Yue, L.; Li, X. Effect of acidity and porosity of alkali-treated ZSM-5 zeolite on eugenol hydrodeoxygenation. Catal. Today 2015, 258, 90-95. [CrossRef]

48. Koekkoek, A.J.J.; Xin, H.; Yang, Q.; Li, C.; Hensen, E.J.M. Hierarchically structured Fe/ZSM-5 as catalysts for the oxidation of benzene to phenol. Micropous Mesoporous Mater. 2011, 145, 172-181. [CrossRef]

(c) 2018 by the authors. Licensee MDPI, Basel, Switzerland. This article is an open access article distributed under the terms and conditions of the Creative Commons Attribution (CC BY) license (http:/ / creativecommons.org/licenses/by/4.0/). 